\title{
Decoupling of helium and Sr-Nd-Pb isotope systems associated with ridge morphology and mantle dynamics of the central North Fiji Basin
}

\author{
JIHYE OH ${ }^{1,2}$, JONGUK KIM ${ }^{1}$, FINLAY M. STUART ${ }^{3}$, MUNJAE \\ PARK $^{2}$, INSUNG LEE ${ }^{2}$
}

${ }^{1}$ Deep-sea and Seabed Mineral Resources Research Center, Korea Institute of Ocean Science \& Technology, Busan, Republic of Korea (glauxo@kiost.ac.kr)

${ }^{2}$ School of Earth and Environmental Sciences, Seoul National University, Seoul, Republic of Korea

${ }^{3}$ Isotope Geoscience Unit, Scottish Universities Environmental Research Center, East Kilbride, UK

We report an association between decoupling of helium from non-volatile isotopes and anomalous topography of spreading ridges controlled by dynamics of hot buoyant mantle lying beneath the central North Fiji Basin. Covariations of topography and $\mathrm{Sr}-\mathrm{Nd}-\mathrm{Pb}$ isotopes with two enrichment peaks near $16^{\circ} 50^{\prime} \mathrm{S}$ triple junction support the hot ascending material distinguished from the depleted upper mantle. Helium isotopes also present double peaks (12 and 9.6 R/Ra) indicating the upwelling initiated from the deep upper mantle (or mantle transition zone), but their positions are shifted to the south relative to those of other isotopic tracers, which can be explained by preferential helium degassing of the plume. Anomalous circular depressions along the spreading axis within volcanic dome of the triple junction, which were found through high-resolution ROV bathymetric mapping, are similar to pre-existing thin spots formed by lateral spreading of the Iceland hotspot. These plume-like geochemical and topographical observations have implication for multi-stage melting process and mantle flow in the study area. The ascending mantle has undergone separation of the melts enriched in helium in the deeper mantle, which formed the high helium anomaly found in the southern region. The displacement of the helium and Sr-Nd$\mathrm{Pb}$ isotope systems could be result of lateral migrations of the separated melts by the southwestward flow of ambient Indiantype MORB mantle in the upper mantle depth. At the uppermost of the asthenosphere, the hot buoyant mantle experienced decompression melting, forming circular melt lense within the axial fissure swarm, as it spread to beneath the pre-existing thin lithosphere of the spreading axis. 